\title{
PERAN PENDIDIKAN DALAM MEMBANGUN KARAKTER BANGSA Oleh:
}

\author{
Andi Agustang \\ andi.agustang@unm.ac.id \\ Andi Dody May Putra A \\ andidodi044@gmail.com \\ Andi Asrifan \\ andiasrifan@gmail.com
}

\section{Pengantar}

Pendidikan merupakan hal fundamental untuk membangun bangsa. Melalui pendidikan terjadi suatu proses transformasi nilai, ilmu pengetahuan, teknologi dan seni. Karena itu, kemajuan suatu bangsa sangat ditentukan oleh kualitas sistem pendidikan yang dianut. Indonesia sebagai salah satu negara berkembang tidak luput dari upaya mencari format dan sistem pendidikan yang tepat sesuai dengan potensi wilayah dan budaya bangsa sendiri. Keinginan kuat untuk sejajar dengan negara maju lainnya, terus diupayakan, namun dengan tetap mempertahankan jatidiri bangsa yang Bhinneka Tunggal Ika. Namun dalam proses perjalanan yang cukup panjang, ternyata bangsa Indonesia menghadapi berbagai masalah dan konflik sehingga keinginan untuk maju dengan berlandaskan jatidiri bangsa sendiri belum dapat tercapai, bahkan cenderung sebaliknya, sudah tidak mencapai kemajuan yang berarti, diiringi pula oleh krisis moral yang sudah berada pada titik yang cukup mengkhawatirkan.

Salah satu persoalan yang dihadapi bangsa Indonesia di bidang pendidikan saat ini adalah bagaimana agar pendidikan mampu membentuk karakter bangsa yang bermartabat. Sebagaimana kita ketahui, pendidikan by design adalah upaya untuk mengembangkan seluruh potensi kemanusiaan anak atau peserta didik ke arah yang lebih baik, lebih berbudaya dan lebih mermartabat. Ketika orang mendengar kata 'pendidikan', yang terbayang pertama kali adalah isinya pasti soal nilai dan sikap yang sengaja ditanamkan kepada si terdidik (transmission of values), dan tentunya adalah nilai dan sikap yang positif, yang 
diharapkan mampu membawa kepada yang bersangkutan menjadi orang yang baik, atau bersikap baik, karena didorong oleh nilai-nilai kebaikan. Seolah-olah tiga aspek rohani manusia sudah tercakup di dalamnya, yakni aspek kognitif, afektif dan konatif. Ketika peserta didik diperkenalkan dengan nilai-nilai kebaikan tertentu untuk selanjutnya ditanamkan atau ditransmisikan kepada mereka, harapannya peserta didik sudah mengetahui atau mengenal nilai-nilai tersebut, kemudian merespons nilai nilai tersebut dengan sikap pribadinya, untuk selanjutnya tergerak hatinya untuk mewujudkan nilai-nilai yang diketahuinya itu agar manifes dan menjadi pendorong untuk melakukan perbuatan baik dan terpuji. Inilah yang seharusnya terjadi (das sollen).

Akan tetapi, jika bertolak dari kejadian sehari-hari, baik dalam lingkungan masyarakat di sekitar tempat kita tinggal, atau ketika kita dalam perjalanan, maupun ketika kita menyaksikan lewat tayangan televisi, maka ternyata (das sein) bayangan kita meleset, karena bertolak belakang dengan apa yang kita bayangkan semula, setidak-tidaknya kurang sesuai dengan yang kita harapkan. Banyak di antara orang yang berpendidikan, ternyata mereka pulalah orang yang merusak citra pendidikan itu sendiri. Seolah-olah nilai dan sikap yang pernah ditanamkan kepada mereka sejak kecil sampai pada jenjang pendidikan tertinggi mereka, belum atau tidak pernah terjadi, atau lenyap begitu saja. Pertanyaan kita tentunya adalah "apa yang salah dari semua ini?" Apakah faktor individunya atau karena faktor lingkungan termasuk faktor pendidikannya?

Ketika banyak warga bangsa kita yang terlibat dalam kasus-kasus korupsi, narkoba, tindak kriminal dan perilaku negatif lainnya, yang notabene dilakukan oleh orang-orang yang berpendidikan, mungkin ada segelintir orang yang mencoba mengaitkan perilaku tersebut dengan karakter atau watak bangsa kita. Orang kemudian mencoba mengaitkan antara pendidikan dengan pembentukan karakter bangsa (nation and character building). Mungkin ada segelintir orang yang beranggapan bahwa istilah tersebut hanya relevan dan populer ketika awal kemerdekaan negeri ini, sehingga bagi generasi sekarang sudah dianggap tidak relevan lagi. Benarkah? Nampaknya kita sepakat bahwa persoalan 
pembentukan karakter bangsa yang bermartabat adalah persoalan bangsa Indonesia dulu, sekarang dan yang akan datang. Dengan kata lain, pembentukan karakter bangsa yang bermartabat adalah harus selalu diupayakan sepanjang jaman secara terus menerus dan berkelanjutan. Di sinilah arti pentingnya pendidikan. Persoalannya adalah pendidikan yang bagaimana yang diharapkan mampu membentuk karakter bangsa yang bermartbata itu?

\section{Manusia dan Pembangunan}

Sebelum membahas lebih lanjut tentang pendidikan yang bagaimana yang diharapkan mampu mebentuk karakter bangsa yang bermartabat, terlebih dahulu kita bicarakan tentang pentingnya manusia dalam pembangunan di segala bidang. Dengan memahami peran manusia dalam pembangunan, kita akan lebih serius melihat persoalan pendidikan termasuk pendidikan karakter. Poespowardojo mengartikan pembangunan sebagai usaha untuk meningkatkan mutu dan taraf hidup masyarakat menjadi lebih baik (Poespowardojo, 1993: 47). Sudah barangtentu peningkatan mutu di sini yang dimaksud adalah bukan hanya pada sektor ekonomis semata, melainkan meliputi seluruh aspek kehidupannya. Dan ukuran yang dipakai untuk menunjukkan perbaikan hidup tersebut dapat berbeda-beda antara orang yang satu dan orang yang lain, atau antara masyarakat yang satu dan masyarakat yang lain, atau antara bangsa yang satu dan bangsa yang lain.

Jika pembangunan dikaitkan dengan manusia, maka dapat dikatakan bahwa pembangunan selalu menunjuk pada manusia. Manusia adalah subyek pembangunan, dan ini berarti manusia adalah pelaksana sekaligus tujuan dari pembangunan itu sendiri. Dalam perspektif ini, pembangunan pada akhirnya tidak akan berhasil jika tidak memperhatikan manusia sebagai pelakunya, karena pada manusialah pembangunan benar-benar mempunyai akar yang kuat. Produksi misalnya, hanya dapat dihasilkan dan dapat diberikan secara kontinyu sepanjang manusia sanggup melaksanakannya. Oleh sebab itu, pembangunan secara struktural berarti membangun manusia

pembangunan. Sebagai pelaksana pembangunan, manusia bukanlah 
mesin yang berjalan secara mekanistis, melainkan pribadi yang bekerja berdasarkan orientasi dan motivasi. Jadi, supaya pembangunan dapat berhasil, harus diberi perhatian khusus pada pelaksana-pelaksana sebagai human invesment. Dengan memperhatikan pelaksana-pelaksana pembangunan berarti memberikan orientasi dan menghidupkan motivasi yang tepat dan benar untuk pembangunan.

Di samping itu, manusia adalah tujuan pembangunan. Justru di sinilah letak perbedaan orientasi kita dengan pandangan komunis yang totaliter. Manusia bukan sekedar sejumlah relasi sosial dan karena itu tidak dapat dinilai semata-mata sebagai faktor dalam masyarakat. Manusia dengan kekayaan sumber daya yang dimilikinya hidup dalam historisitas, namun hal itu tidak berarti bahwa eksistensi ditentukan dan bergantung sama sekali pada sejarah. Manusia adalah pribadi dan karena itu merupakan panggilan (afgabe) yang harus membangun untuk menentukan sejarah (Poespowardojo, 1993: 54-55). Dari uraian ini jelas, bahwa dalam pembangunan yang pertama dan utama yang menjadi fokus adalah manusianya, karena manusia adalah pelaku sekaligus tujuan pembangunan itu sendiri. Sebagai pelaku pembangunan dia sangat menentukan corak masyarakat seperti apakah yang hendak diwujudkan.

\section{Pengertian Karakter}

Di atas telah disampaikan bahwa manusia adalah subyek dan pelaku pembangunan, dan karena dia adalah subyek dan pelaku pembangunan di semua aspek kehidupan, maka dia harus memiliki karakter yang baik dan bermartabat agar amanah yang diberikan kepadanya dapat dilaksanakan dengan sebaik-baiknya. Di sinilah pentingnya pendidikan karakter. Sebelumnya perlu dicari jawabannya dahulu terhadap pertanyaan: apakah karakter atau watak itu? Karakter atau watak adalah paduan dari segala tabiat manusia yang bersifat tetap, sehingga menjadi "tanda" yang khusus untuk membedakan orang yang satu dari orang yang lain. Dalam bahasa Yunani dan Latin, "character" itu berasal dari perkataan "charassein" yang artinya mengukir corak yang tetap dan tidak terhapuskan. Karakter itu terjadinya karena perkembangan dasar yang telah terkena pengaruh dari ajar. Yang dinamakan "dasar" adalah bekal 
hidup atau "bakat"nya anak dari alam sebelum lahir, yang sudah menjadi satu dengan kodrat hidupnya anak (biologis). Sedangkan ynag disebut "ajar" adalah segala sifat pendidikan dan pengajaran mulai anak dalam kandungan ibu hingga akil balig, yang dapat mewujudkan intelligibel, yakni tabiat yang dipengaruhi oleh masaknya angan-angan. Di dalam jiwa, karakter itu adalah imbangan yang tetap antara hidup batinnya seseorang dengan segala macam perbuatannya. Oleh sebab itu, seolaholah menjadi "lajer" atau "sendi" di dalam hidupnya, yang lalu mewujudkan sifat perangai yang khusus buat satu-satunya manusia (Ki Hadjar Dewantara, 1977: 407-408)

Imam Barnadib (1978: 14) mengartikan watak atau karakter dalam arti psikologis dan etis. Dalam arti psikologis, watak adalah sifat-sifat yang demikian nampak dan yang seolah-olah mewakili pribadinya. Sedangkan dalam arti etis, watak harus mengenai nilai-nilai yang baik dan menunjukkan sifat-sifat yang selalu dapat dipercaya, sehingga orang yang berwatak itu menunjukkan sifat mempunyai pendirian yang teguh, baik, terpuji dan dapat dipercaya. Dengan demikian, watak berarti susunan batin atau kesatuan kepribadian dalam arti etis, dan jika hal ini dihubungkan dengan definisi kepribadian menurut pengertian pendidikan, maka kepribadian yang demikian inilah yang memenuhi syarat dalam arti pedagogis. Berwatak berarti memiliki prinsip dalam arti moral. Oleh sebab itu, watak yang tidak bermoral perlu dicegah kehadirannya dalam pergaulan hidup manusia. Hanya dengan cara ini perbuatan dapat dipertanggung jawabkan dalam arti moral. Berdasarkan pandangan tersebut, Imam Barnadib menandaskan bahwa masalah watak berhubungan dengan masalah keagamaan. Agama mendidik manusia mengenal kebaikan dan berbuat yang baik, dan demikian pula pendidikan watak. Maka dari itu, pendidikan watak menjadi salah satu pendukung dari pendidikan agama.

Membentuk watak atau karakter bangsa yang bermartabat bukanlah perkara mudah, karena dibutuhkan political will atau komitmen, utamanya dari pihak pemerintah atau penguasa yang memiliki power. 
Sejarah Indonesia telah mencatat bahwa pada dua dasa warsa pasca kemerdekaan Republik Indonesia, pembangunan nasional yang digarap pertama kali adalah di bidang politik yakni membangun bangsa dan karakter seluruh masyarakat Indonesia yang berisi semangat nasionalisme, rasa cinta kepada tanah air (Wibisono, 1998: 8; Poespowardojo, 1991: 2). Baru pada tahapan pembangunan selanjutnya bidang ekonomi mulai digarap. Dan pembangunan bidang-bidang yang lain ikut digarap seiring dengan perkembangan dalam dan luar negeri, termasuk karena didorong oleh banyaknya kritik yang diarahkan pada paradigma pertumbuhan ekonomi yang berdampak negatif pada rusaknya lingkungan hidup dan diabaikannya pembangunan sosialbudaya. Atas dasar ini, maka konsep dan paradigma pembangunan berkelanjutan (sustainable developmnet) kemudian mulai mendapat perhatian semua kalangan, baik di tingkat nasional maupun global. Konsep dan paradigma ini mencoba mengakomodasi berbagai paradigma pembangunan, baik yang berasal dari pendukung paradigma pertumbuhan ekonomi, maupun dari kelompok pendukung paradigma lingkungan hidup dan sosial-budaya. Konsep dan paradigma pembangunan berkelanjutan juga sangat memperhatikan nasib generasi mendatang, karena dengan mengadakan pembangunan di bidang ekonomi, otomatis menggunakan sumber daya alam secara tidak terkontrol. Jika sumberdaya alam terkuras habis karena sangat bernafsu untuk mengadakan pembangunan, maka bagaimana nasib generasi mendatang? Demikian argumentasi kelompok pendukung konsep dan paradigma pembangunan berkelanjutan (Tjokrowinoto, 2002: 11).

\section{Peran Ilmu Pendidikan dalam pembentukan karakter bangsa yang bermartabat}

Dalam upaya membentuk karakter bangsa yang bermartabat, peran ilmu pendidikan sangat penting, karena dalam ilmu pendidikan kita dapat menemukan banyak konsep maupun teori pendidikan yang dapat dijadikan acuan untuk mengembangkan seluruh potensi kemanusiaan termasuk karakter atau wataknya. Dalam Ilmu pendidikan juga dijelaskan bagaimana pendidikan itu sebaiknya dilaksanakan. Benarkah pendidikan memegang peranan penting dalam pembangunan, utamanya 
dalam membentuk watak bangsa yang bermartabat? Pendidikan yang bagaimana yang dapat membentuk karakter bangsa yang bermartabat itu? Plato memiliki gagasan tentang pendidikan. Gagasannya tentang pendidikan sebenarnya untuk menjawab persoalan bagaimana menimbang dan memilih para penjaga negara yang tidak hanya beringas dan sewenang-wenang terhadap sesama warga negara, tetapi juga yang tidak membahayakan eksistensi negara itu sendiri? Secara singkat, siapa "yang cocok" untuk menjadi penjaga negara? Dari pertanyaan tersebut kemudian disepakati bahwa para penjaga harus dipilih, dan kriteria untuk memilihnya adalah mereka yang berindera tajam, cekatan dalam memahami segala persoalan, kuat, berani, dan memiliki jiwa yang bersemangat. Di sini lalu timbul pertanyaan, bagaimana dapat diperoleh para penjaga dengan sifat-sifat semacam ini? Salah satu jawabannya adalah melalui pendidikan. Menurut Plato, pendidikan adalah alat pembentukan karakter, baik bagi para penjaga maupun bagi seluruh warga negara (dalam Jena, 2002: 54-55).

Moh Syafei, pendiri INS (Indonesische Nederland School) Kayutanam Sumatra Barat sangat menekankan agar bangsa Indonesia memiliki watak yang merdeka. Sarana untuk membentuk watak yang merdeka ini ialah dengan memberikan alat yang akan menyadarkannya bahwa mereka (anak didik, para pemuda dan segenap warga negara) mempunyai kemampuan untuk berbuat segala yang berguna bagi kehidupannya sendiri dan bagi orang lain di dalam lingkungan hidupnya. Yang berkewajiban memberikan alat itu ialah sekolah yaitu dengan memberikan kesempatan kepada setiap anak untuk tumbuh menurut kodrat yang ditakdirkan Tuhan kepadanya. Menurutnya, sistem pendidikan yang mencetak setiap orang sehingga memiliki keseragaman kecakapan dan ilmu adalah bertentangan dengan kodrat insaniah. Dengan dasar konsepsi di atas, INS Kayutanam didirikan dengan memakai sistem sekolah kerja yang kreatif. Untuk itu, sekolah menyediakan sebanyak-banyaknya dan selengkap-lengkapnya fasilitas pendidikan yang dapat menampung pengembangan bakat anak sesuai dengan kodrat lahir dan kodrat batin seperti: otak, hati, dan tenaga yang fungsinya seimbang bagi setiap orang. Dalam mengembangkan bakat ini, 
anak didik harus diletakkan sebagai subyek dan kewajiban guru hanya memberikan tuntunan apabila perlu. (Depdikbud, 1985: 51-52).

Seperti Taman Siswa, INS juga menekankan pentingnya asrama bagi anak didik. Manfaat asrama ini tidak hanya membentuk suatu lingkungan hidup untuk berinisiatif dan berkreasi, tetapi juga untuk membangun naluri positif bagi pembinaan semangat setia kawan dan bertenggang rasa antar sesama manusia yang memiliki berbagai pandangan hidup dan pembawaan. Dalam suasana seperti ini sifat-sifat berdisiplin, bertanggung jawab dan tekun dalam bekerja, cermat dalam pemeliharaan dan perawatan milik bersama dan miliki pribadi diharapkan akan timbul dan berkembang menggantikan kebiasaan yang negatif.

Meskipun diyakini pendidikan dapat membentuk karakter bangsa, sebagaimana telah disebutkan di atas. Juga, disebutkan lagi dalam UU RI Nomor 20 Tahun 2003 tentang Sisdiknas pasal 3 bahwa pendidikan nasional berfungsi mengembangkan kemampuan dan membentuk watak serta peradaban bangsa yang bermartabat dalam rangka mencerdaskan bangsa. Tetapi dalam kenyataan sejarah bangsa kita, pembangunan manusia lewat pendidikan bergeser fungsinya dari fungsi menanamkan ideologi dan mewariskan nilai-nilai budaya bangsa kepada generasi baru ke fungsi ekonomis, yakni mempersiapkan tenaga kerja untuk bisa berpartisipasi dalam proses produksi. Jika fungsi pertama lebih menekankan fungsi pendidikan sebagai gejala kebudayaan, di mana pendidikan berfungsi untuk menciptakan members of the nation-state, sebagai warga negara yang baik, yang sadar akan hak dan kewajibannya sebagai anggota suatu masyarakat bangsa. Fungsi kedua pendidikan lebih sebagai gejala ekonomi, yakni mempersiapkan seseorang untuk memasuki pasar tenaga kerja lewat serangkaian proses pembelajaran. Adanya pergeseran fungsi pendidikan ini tentu bukan tanpa alasan. Alasannya, karena proses pendidikan tidak berlansung dalam ruang kosong atau dalam kefakuman, melainkan berada di tengah-tengah perubahan masyarakat. Dalam ungkapan yang lebih spesifik, proses pendidikan itu berinteraksi dengan "dunia lain", utamanya dunia politik 
dan ekonomi. Bahkan dunia lain tersebut berupaya keras untuk dapat mendominasi dunia pendidikan. (Zamroni, 1993: 147-8).

Dari kenyataan tersebut, maka untuk mebangun karakter bangsa yang bermartabat diperlukan political will atau komitmen dari pemerintah atau penguasa. Mengapa? Karena sejarah telah membuktikan bahwa pemerintah atau penguasa sangat menentukan dalam membentuk karakter bangsa, setidak-tidaknya hal itu telah dipraktekkan pada dua dasa warsa pasca kemerdekaan negeri ini dengan penekanan pada upaya membangun semangat nasionalisme. Bahkan pemerintah merupakan kekuatan utama yang mampu menentukan arah dan kebijakan pendidikan, di samping yang paling mampu menyediakan fasilitas pendidikannya. Ini berarti, arah dan kebijakan pendidikan banyak dipengaruhi oleh kepentingan ekonomi dan juga oleh kepentingan politik. Kalau keduanya berkolaborasi untuk menekan dan mendominasi pendidikan, maka akan muncul apa yang dinamakan eco-paedagogical dictatorship (Zamroni, 1993: 149).

Dengan adanya kesadaran bahwa proses pendidikan berlangsung dalam masyarakat yang selalu berubah (Fagerlind and Saha, 1983: 196), yang berinteraksi dengan dunia lain, utamanya dengan dunia politik dan ekonomi, maka menjadi tidak mungkin, jika kita bangsa Indonesia hanya mempertahankan fungsi konservatif pendidikan tanpa terlibat dalam fungsi pendidikan yang lain yakni fungsi pengembangan sumber daya manusianya. Dengan fungsi ini pendidikan juga ikut mempersiapkan lulusannya memasuki dunia kerja. Meskipun demikian, bangsa Indonesia harus tetap pada komitmennya dan merealisasikan komitmennya untuk lebih mengedepankan aspek moralitas bangsa dalam kiprah pembangunannya, dan itu berarti pendidikan nilai, pendidikan watak dan pendidikan moral harus lebih dikedepankan daripada pendidikan yang lainnya, karena pendidikan nilai, karakter atau watak dan moral melandasi aspek-aspek pendidikan yang lain.

DAFTAR PUSTAKA 
Barnadib, Imam (1978). Filsafat Pendidikan (Tinjauan Mengenai Beberapa Aspek dan Proses Pendidikan). Yogyakarta: Penerbit "STUDING".

Departemen Pendidikan dan Kebudayaan (1985). Materi Dasar Pendidikan Program Akta Mengajar V.: Buku II Dasar Ilmu Pendidikan. Jakarta: Penerbit Universitas Terbuka.

Dewantata, Ki Hadjar (1977). Bagian Pertama: PENDIDIKAN. Yogyakarta: Diterbitkan oleh Majelis Luhur Persatuan Taman Siswa.

Fagerlind, Ingemar and Lawrence J. Saha (1983). Education and National Development: A Comparative Perspective. Oxford: PERGAMON PRESS.

Jene, Jeremias (2002). "Pendidikan sebagai Kontrol Sosial dan Kebebasan Individu: Diskursus mengenai Pendidikan menurut Plato" dalam Majalah Filsafat Driyarkara. Th. XXV Nomor 4, April 2002.

Pospowardojo, Soerjanto (1991). Pembangunan Nasional dalam Perspektif Budaya: Suatu Pendekatan Filsafat. . Pidato Pengukuhan guru Besar Tetap dala Ilmu Filsafat pada fakultas sastra Universitas Indonesia di jakarta pada tanggal 30 November 1991.

(1993). Strategi Kebudayaan: Suatu Pendekatan Filosofis. Jakarta : Penerbit PT Grameia bekerja sama dengan dengan LPSP (Lembaga Pengkajian Strategi dan Pembangunan).

Tjokrowinoto, Moeljarto (2002). Pembangunan Dilema dan Tantangan. Cetakan IV. Yogyakarta: Penerbit Pustaka Pelajar.

Wibisono, Koento (1998). "Wawasan Kebangsaan dalam Era Reformasi" dalam Jurnal Filafat Pancasila. Edisi Nomor 2 Thn.II, Desember 1998.

Zamroni (1993).'Perkembangan Pendidikan dalam bayang-bayang Ekonomi: Perlunya Kekuatan Nasional Pendidikan" dalam Prospektif. Volume 5 Nomor 3, tahun 1993.. 


\section{BACAAN TAMBAHAN}

Abdurachman, A. D. M. P. A., \& Agustang, A. Culture Of Shame-Heart And Social Solidarity Of Kaitetu People Central Maluku District, Indonesia.

Agustang, A., Badwi, A., Agustang, A. T. P., \& Rasyid, R. (2019, December). Tindakan Hipokrit Terhadap Kondom dalam Dinamika Hubungan Sosial (Studi Kualitatif Pada Masyarakat Kota Makassar). In Seminar Nasional LP2M UNM.

Agustang, A., \& Oruh, S. Factors affecting of heropnam of mental disorders in Dadi Regional Hospital in South Sulawesi Province. Man In India, 97(11), 233-244.

Agustang, S. O. A., \& Bagu, A. A. KEJADIAN HEROPNAM GANGGUAN JIWA DAN FAKTOR YANG MEMPENGARUHI PADA RUMAH SAKIT KHUSUS DAERAH DADI PROVINSI SULAWESI SELATAN.

Agustang, A. (2011). Filosofi Research (Dalam Upaya Pengembangan Ilmu).

Agustang, A. (2020). Symbolic Violence towards Students in the Context of the Existence of the Stereotypical Frames of Lecturers and Students in the Higher Education System in Indonesia. PalArch's Journal of Archaeology of Egypt/Egyptology, 17(2), 249-258.

Agustang, A. (2020). The Symbolic Violence Towards Private School Students Through The Frame Stereotype In Bantaeng District Of Indonesia. Prosiding ICoISSE, 1(1), 578588.

Agustang, A. (2007). Entaskan Kemiskinan: Analisis Kinerja Pembangunan Indonesia. Makassar: Indobis Publisher.

Agustang, A., Pada, A. T., \& Bastiana, M. (2018, October). Social Interaction of Local Communities With Migrants and Changes in The Structure of Local Communities (Study on Plural Society in Makassar Industrial Area). In 1st International Conference on Social Sciences (ICSS 2018). Atlantis Press.

Agustang, A., \& Asrifan, A. (2021, January 15). MUHAMMADIYAH DALAM GERAKAN SOSIAL DI KABUPATEN WAJO. https://doi.org/10.31219/osf.io/dpsg9

Agustang, A., Mutiara, I. A., \& Asrifan, A. (2021, January 10). Masalah Pendidikan di Indonesia. https://doi.org/10.31219/osf.io/9xs4h

Agustang, A. (2021, January 10). INTERAKSI SOSIAL KOMUNITAS LOKAL DENGAN PENDATANG DAN PERUBAHAN STRUKTUR KOMUNITAS LOKAL (Studi pada Masyarakat Majemuk di Kawasan Industri Makassar). https://doi.org/10.31219/osf.io/pw5xr

Agustang, A. (2021, January 10). INTERAKSI SOSIAL KOMUNITAS LOKAL DENGAN PENDATANG DAN PERUBAHAN STRUKTUR KOMUNITAS LOKAL (Studi pada Masyarakat Majemuk di Kawasan Industri Makassar). https://doi.org/10.31219/osf.io/pw5xr 
Agustang, A. (2021, January 10). KERAJINAN TENUN PADA MASYARAKAT MUNA (Kasus Peranan Modal Manusia dan Modal Sosial Dalam Reproduksi Budaya Tenun di Kabupaten Muna). https://doi.org/10.31219/osf.io/4bksf

Agustang, A., Ariani, A. I., \& Asrifan, A. (2021, January 10). KONSTRUKSI SOSIAL JANDA TEREKSPLOITASI (STUDI KASUS DI KELURAHAN TETEBATU KECAMATAN PALLANGGA KABUPATEN GOWA). https://doi.org/10.31219/osf.io/ryz2k

Agustang, A. (2008). Masjid Tua Katangka Dari Ritual Hingga Fungsi Sosial.

Agustang, A. (2021, January 10). IMPROVING THE QUALITY OF PRIMARY HEALTH SERVICES IN THE PERSPECTIVE OF PARTICIPATORY GOVERNANCE. https://doi.org/10.31219/osf.io/4kx6e

Agustang, A., Ahriani, A., \& Asrifan, A. (2021, January 10). MARGINALISASI BUDAYA (STUDI PADA PRANATA SOSIAL MASYARAKAT MUSLIM SUKU KOKODA KOTA SORONG). https://doi.org/10.31219/osf.io/942y8

Agustang, A. (2021, January 10). HEGEMONIC SOCIAL RELATION A Study of Sociology on Outsourcing Practice. https://doi.org/10.31219/osf.io/78xqg

Agustang, A., Mutiara, I. A., \& Asrifan, A. (2021, January 10). Genealogi Stigma Sosial Terhadap Pasien Covid 19. https://doi.org/10.31219/osf.io/ep7jf

Agustang, A., \& Indah, A. M. Andi Asrifan. 2021.“. KONSTRUKSI SOSIAL JANDA TEREKSPLOITASI (STUDI KASUS DI KELURAHAN TETEBATU KECAMATAN PALLANGGA KABUPATEN GOWA).” OSF Preprints. January, 10.

Agustang, A., Ariani, A. I., \& Asrifan, A. (2021, January 10). KONSTRUKSI SOSIAL JANDA TEREKSPLOITASI (STUDI KASUS DI KELURAHAN TETEBATU KECAMATAN PALLANGGA KABUPATEN https://doi.org/10.31219/osf.io/ryz2k

Agustang, A., \& Asrifan, A. (2021, January 9). BAHAN MATA KULIAH MATA KULIAH PSYCHOLINGUISTICS. https://doi.org/10.31219/osf.io/n8j6t

Agustang, A. (2021, January 9). KESEJAHTERAAN PSIKOLOGIS (Studi Pada Dewasa Madya yang Belum Menikah di Kota Makassar). https://doi.org/10.31219/osf.io/v5af8

Agustang, A. (2021, January 9). PENGARUH PENGETAHUAN KELUARGA, STIGMA MASYARAKAT DAN KEPATUHAN MINUM OBAT TERHADAP KEKAMBUHAN PENYAKIT GANGGUAN JIWA DI KOTA MAKASSAR. https://doi.org/10.31219/osf.io/wxsg8

Agustang, A., Suardi, I. A. M., Mutiara, I. A., \& Ramlan, H. (2020). SOCIAL PRENEUR DALAM PENANGGULANGAN KEMISKINAN DI KECAMATAN BISSAPPU KABUPATEN BANTAENG. Martabe: Jurnal Pengabdian Kepada Masyarakat, 3(2), 331-342.

Agustang, A., Saleh, S., Rasyid, R., \& Agustang, A. T. P. (2019, November). Pengembangan profesionalisme guru SMP Negeri 1 Duampanua Kabupaten Pinrang melalui pelatihan 
penulisan karya tulis ilmiah. In Seminar Nasional Pengabdian Kepada Masyarakat (Vol. 2019, No. 2).

Agustang, A. (2006). Defleksi Sosio-Kultural Masyarakat Maritim Ke Arah Kepentingan Pembangunan (Studi Kasus Pada Komunitas Nelayan di Kabupaten Selayar Provinsi Sulawesi Selatan). Disertasi. Program Pascasarjana Universitas Padjajaran. Bandung.

Agustang, S. O. A., \& Bagu, A. A. KEJADIAN HEROPNAM GANGGUAN JIWA DAN FAKTOR YANG MEMPENGARUHI PADA RUMAH SAKIT KHUSUS DAERAH DADI PROVINSI SULAWESI SELATAN.

Agustang, A., Badwi, A., Agustang, A. T. P., \& Rasyid, R. (2019, December). Tindakan Hipokrit Terhadap Kondom dalam Dinamika Hubungan Sosial (Studi Kualitatif Pada Masyarakat Kota Makassar). In Seminar Nasional LP2M UNM.

Agustang, A., Ihsan, A., \& Suhaeb, F. (2015). POVERTY AND MODERNIZATION IN BAJO FISHING COMMUNITY. International Journal of Academic Research, 7.

Agustang, A. T. P., Said, M., \& Rasyid, R. (2016, September). PERKEMBANGAN PERAN JENDER DALAM PRESPEKTIF TEORI ANDROGINI. In Prosiding Seminar Nasional Himpunan Sarjana Ilmu-ilmu Sosial (Vol. 1, No. 1, pp. 116-123).

Agustang, A. (2014). LIFE BEHAVIOR OF SOCIETY, FIVE CASES ON FAMILY OF DIABETES MELLITUS PATIENTS IN MAKASSAR. International Journal of Academic Research, 6(1).

Alim, A. (2011). Evaluasi Program Pemberian Bubuk Taburia Di Kota Makasar. Unhas. Makasar.

Al Yakin, A., \& Agustang, A. SELEBRIFIKASI DAN ELEKTABILITAS; MENAKAR RESPON PUBLIK.

Amran, N. G., \& Agustang, A. (2020). Implementasi Kurikulum 2013 Dalam Peningkatan Kompetensi Psikomotorik Dan Afektif Siswa. Phinisi Integration Review, 3(2), 179184.

AM, S. A., Agustang, A., Mustadjar, M., \& Tahmir, S. (2020). Mobility and Social Change of the Economy of Indonesian Migrant Workers in Indonesia. Solid State Technology, 63(5), 408-417.

Arwan, A., Agustang, A., Arlin, A., Yani, A., \& PUTRA, D. M. (2019). Contestation of Elite Discourse in Treatment of HIV and AIDS. Iranian Journal of Public Health, 48(12), 2205.

Aswan, A., \& Agustang, A. (2017). PERIAKU ANOMI (STUDI PADA SISWA DI SMP NEGERI 21 MAKASSAR). JURNAL SOSIALISASI, 62-66.

Ardiansyah, A. A., \& Agustang, A. (2018). MAHASISWI BERKELUARGA DI FAKULTAS ILMU SOSIAL UNIVERSITAS NEGERI MAKASSAR. JURNAL SOSIALISASI, 19-23. 
Arlin, A. D. A. M., \& Andi, A. L. I. M. (2020). Effect of Role Ambiguity and Fatigue on Employee Performance in Pelamonia Hospital, Makassar, Indonesia. Iranian Journal of Public Health, 49(1), 203.

Arisal, A., Agustang, A., \& Syukur, M. (2020). Diskriminasi Sosial Anak Penderita Kusta di Kota Makassar. Phinisi Integration Review, 3(2), 297-304.

Asri, A., Kasnawi, T., \& Agustang, A. Actors' Social Tensions on Traditional Birth Attendants and Midwife Partnerships in Childbirth Assistance (Sociology of Health Study in Bulukumba Regency).

Asyikin, A., Agustang, A., Sani, Y., \& Samad, S. (2014). PATIENT AND PHARMACIST INTERACTIONS IN SELF MEDICATION IN MAKASSAR. International Journal Of Academic Research, 6(2).

Aida, K. N., Andi, A., \& Arlin, A. (2019). THE ULAYAT RIGHT TO THE SEA IN ARU ISLANDS DISTRICT OF INDONESIA: A STUDY OF FISHERIES RESOURCES MANAGEMENT BASED ON CUSTOMARY COMMUNITY. Russian Journal of Agricultural and Socio-Economic Sciences, 95(11).

Aida, K. N., Agustang, A., Arlin, A., \& Agustang, A. D. M. The Patron-Client Relationship Patterns In Siwa Lima Fishermen Community, Aru Islands District Maluku, Indonesia.

Badwi, A., Agustang, A., \& Adam, A. Individual Cognitive Dissonance in Society on Condom (A Sociology of Health Study in Makassar City).

Bastiana, B., Agustang, A., Jumadi, J., \& Najamuddin, N. (2019, December). Karakteristik Umum dan Tingkat Pendapatan Pedagang Kaki Lima (PKL) Kota Makassar. In Seminar Nasional LP2M UNM.

Bintaha, M., Salman, D., Agustang, A., \& Suhaeb, F. W. (2014). THE ROLE OF SOCIAL CAPITAL TOWARD SOME OTHER CAPITALS FOR RURAL ADVANCEMENT. International Journal of Academic Research, 6(5).

Chalid, I., Adam, A., \& Alim, A. (2018). PENGARUH PENYULUHAN DAN KONSUMSI MINUMAN LOKAL TERHADAP TEKANAN DARAH IBU HAMIL DI PUSKESMAS KASSI-KASSI KOTA MAKASSAR TAHUN 2017. Jurnal Mitrasehat, 8(2), 179-185.

Dirawan, G. D. FOSTERING COLLABORATION STREET CHILDREN IN MAKASSAR. Man In India, 95(3), 569-576.

Djalante, A., Agustang, A., Tahmir, S., \& Sahabuddin, J. A Disadvantaged Tribe in Bajoe Village, Bone Regency: A Phenomenological Research on Bajo Tribe's Social Life in Bone Regency, South Sulawesi.

Haniah, S., Agustang, A., \& Samad, S. (2014). SOCIAL ACTION IN THE CLASSROOM: ANALYSIS OF EDUCATIONAL SOCIOLOGY ON INTERACTION BETWEEN TEACHER AND STUDENT IN SMP KARTIKA CHANDRA MAKASSAR. International Journal of Academic Research, 6(4). 
Harman, H., \& Agustang, A. (2020). PERUBAHAN SOSIAL MASYARAKAT PERMANDIAN WAE TUO DESA WAE TUO KECAMATAN KAJUARA KABUPATEN BONE. Jurnal Sosialisasi: Jurnal Hasil Pemikiran, Penelitian dan Pengembangan Keilmuan Sosiologi Pendidikan, (2), 1-7.

Hariati, H., Bagu, A. A., \& Thamrin, A. I. (2019). Kejadian Anemia Pada Ibu Hamil. Jurnal Ilmiah Kesehatan, 1(1), 8-17.

Hasan, I. R., Agustang, A., Kahar, F., \& Tahir, H. (2019). Super Service Delivery": an advanced conceptual model of one-stop service for wide administrative region. Problems and perspectives in management, (17, Iss. 1), 189-201.

Hikmah, N. (2017). PERAN POST TEST TERHADAP MOTIVASI BELAJAR PADA $\begin{array}{llllll}\text { MATA PELAJARAN SOSIOLOGI SISWA } & \text { DI SMA NEGERI } & 11\end{array}$ MAKASSAR. JURNAL SOSIALISASI.

Irawati, A. A., \& Syukur, M. The Mystery of Ecological and Socio-Cultural Degradation Of Bajo Community (A Study Of Nickel Mining Expansion In Pomalaa Sub-District, Kolaka Regency).

Jumharyanti, J., \& Agustang, A. (2018). REMITANSI TENAGA KERJA INDONESIA PASCA KEPULANGAN DARI LUAR NEGERI (STUDI TKI DI DESA WORO KECAMATAN MADAPANGGA KABUPATEN BIMA NTB). JURNAL SOSIALISASI, 68-73.

Kasnawi, T., \& Agustang, A. (2014). TRADITIONAL ELITE ON MODERN POLITICS AT SOUTH SULAWESI. International Journal of Academic Research, 6(4).

Kasnawi, T., Agustang, A., \& Suhaeb, F. (2015). MUHDI AKBAR: NURSERY OF LOCAL MULTICULTURAL IN SELAYAR. International Journal of Academic Research, 7(1).

Kubangun, N., Agustang, A., \& Adam, A. (2020, October). Subaltern and Network Strategy Towards Fishermen Community in Aru Islands District. In 3rd International Conference on Social Sciences (ICSS 2020) (pp. 585-588). Atlantis Press.

Machmuddin, H., Oruh, S., \& Agustang, A. PRIMARY HEALTH SERVICES IN THE PERSPECTIVE OF PARTICIPATORY GOVERNANCE.

Maliang, M. I., Imran, A., \& Alim, A. (2019). Sistem Pengelolaan Rekam Medis (Studi Kualitatif Di Puskesmas Tamalate Makassar Tahun 2019). Window of Health: Jurnal Kesehatan, 315-328.

Masita, M., \& Agustang, A. (2020). Pergeseran Pemaknaan Perayaan Tradisi Saiyyang Pattu'duq di Tinambung Polewali Mandar. Phinisi Integration Review, 3(2), 173-178.

Matakena, F., Watloly, A., Agustang, A., Adam, A., \& Alim, A. (2020). The Self-Concept of Ale Rasa Beta Rasa in the Orang Basudara Community in Ambon (Studies on the Community of Passo and Batumerah Country). International Journal, 9, 1307.

Muhammad, S., Agustang, A., \& Samad, S. (2015). SOCIAL MOVEMENT IN A MINING PROJECT: A STUDY OF SOROWAKOAN CONTENTIOUS POLITICS 
TOWARDS PT VALE INDONESIA, TBK. IN SOROWAKO, SOUTH SULAWESI. International Journal of Academic Research, 7.

Muslimin, A., Idris, R., \& Agustang, A. (2015). CHILDREN AND SOCIAL ENVIRONMENT OF EDUCATION. International Journal of Academic Research, 7.

Muis, I., Agustang, A., \& Adam, A. Lansia Miskin: Demografi Sosial, Distribusi Pekerjaan, Masalah Kesehatan \& Perlindungan Sosial.

Mustadjar, M., \& Agustang, A. (2020). Pergeseran Pola Interaksi Sosial (Studi Pada Masyarakat Banggae Kabupaten Majene). Phinisi Integration Review, 3(2), 138-149.

Mutiara, I. A., Agustang, A., Adam, A., Upe, A., \& Equatora, M. A. (2020). The dynamics of prostitutes lives in metropolitan cities. Journal of Critical Reviews. https://doi. org/10.31838/jcr, 7, 165.

Mufidah, N. F., \& Agustang, A. (2020). STUDI SOSIOLOGI PERNIKAHAN MUBARAK DI PONDOK PESANTREN HIDAYATULLAH MAKASSAR. Jurnal Sosialisasi: Jurnal Hasil Pemikiran, Penelitian dan Pengembangan Keilmuan Sosiologi Pendidikan, (1), 1-8.

Nonci, N., Salman, D., \& Agustang, A. (2014). SILARIANG: STUDY OF THE SOCIAL CONSTRUCTION OF ETHNIC IN MAKASSAR IN GOWA DISTRICT. International Journal of Academic Research, 6(1).

Nurhidayah, I., \& Agustang, A. (2018). PENDIDIKAN SEKS BAGI ANAK REMAJA (STUDI PADA ORANGTUA BERPENDIDIKAN MENENGAH DI KELURAHAN KARUWISI KECAMATAN PANAKKUKANG KOTA MAKASSAR. JURNAL SOSIALISASI, 62-67..

Nur, H., Adam, A., Alim, A., \& Ashriady, A. (2019). Edukasi IMD terhadap Pemberian ASI Eksklusif di Puskesmas Mapilli Kecamatan Mapilli Kabupaten Polewali Mandar. Jurnal Kesehatan Manarang, 5(2), 114-124.

Nur, S., Agustang, A., \& Adam, A. (2020). Uninhabitable Home: Portraits of Poverty in Cities. Indonesian Journal of Social and Environmental Issues (IJSEI), 1(3), 235-240.

Oruh, S., \& AGUSTANG, A. (2019). PENGARUH PENGETAHUAN KELUARGA, STIGMA MASYARAKAT DAN KEPATUHAN MINUM OBAT TERHADAP KEKAMBUHAN PENYAKIT GANGGUAN JIWA DI KOTA MAKASSAR.

Pettalongi, A., Idris, R., Kasnawi, T., \& Agustang, A. (2015). PROMOTING SOCIAL VALUES IN BUILDING SOCIAL INTERACTION AMONG INTER-ETHNICAL STUDENTS IN SMA KARUNA DIPA, PALU. International Journal of Academic Research, 7.

Radillah, R., Alim, A., \& Hidayat, H. (2017). Sanitation Of Chicken Slaughtering Bussiness With Critical Disorders. PROMOTIF: Jurnal Kesehatan Masyarakat, 7(1), 36-51.

Rahman, N., Agustang, A., Akib, H., \& Tahmir, S. (2015). ANALYSIS OF THE DETERMINANT FACTORS OF IN THE LEGISLATIVE PROCESS OF REGIONAL HOUSE OF PEOPLES'REPRESENTATIVES IN TAKALAR REGENCY. International Journal of Academic Research, 7. 
Rahman, B., Agustang, A., \& Samad, S. (2015). HEGEMONIC SOCIAL RELATION, A STUDY OF SOCIOLOGY ON OUTSOURCING PRACTICE. International Journal of Academic Research, 7.

Rasyid, R., Agustang, A., Agustang, A. T. P., Bastiana, B., \& Najamuddin, N. Analisis Faktor Yang Mempengaruhi Status Kemiskinan Rumah Tangga Pada Wilayah Central Bussiness District (CBD) di Kota Makassar. Majalah Geografi Indonesia, 34(1), 4352.

Rongrean, B., Abustan, I., \& Agustang, A. (2015). THE SOCIAL DYNAMICS OF PEDICAB DRIVER TOWARD CLIMATE CHANGES IN MAKASSAR. International Journal of Academic Research, 7.

Rusli, M., Bulkis, S., \& Agustang, A. Usage of Social Capital in Supporting the Welfare of the Coastal Community.

Rieuwpassa, S., Agustang, A., \& Adam, A. Sustainable Peace Development In Ambon (An Analysis Study In Negeri Hila And Dusun Hila Tanah Putih).

Saeni, R., \& Agustang, A. (2014). INDUSTRIAL FACTORY AND LOCAL COMMUNITIES ON THE MARGINAL CITY OF MAKASSAR. International Journal of Academic Research, 6(4).

Sahabuddin, E., Agustang, A., Manda, D., \& Oruh, S. (2020). Partisipasi Sosial Dalam Pemenuhan Activity Daily Living (Adl) Orang Dengan Gangguan Jiwa Di Kota Makassar. Phinisi Integration Review, 3(2), 290-296.

Salmah, A. U., Agustang, A., Idris, R., \& Maidin, A. (2014). Phenomenological Study Of Breast Cancer Patient At Wahidin Sudirohusodo Hospital Makassar; Socio-Cultural Transformation Perspective, 2014. International Journal Of Academic Research, 6(6), 91-95.

Suaib, S., Nawawi, J., Tahmir, S., \& Agustang, A. (2015). ACCOUNTABILITY OF POLICY AND PROGRAM OF BUREAUCRACY AT MINISTRY OF TRANSPORTATION FOR PUBLIC SERVICES IN TERMINAL STATION OF PETTA PONGGAWAE BONE REGENCY, INDONESIA. International Journal of Academic Research, 7(1).

Sulaiman, U., Idris, R., Ardi, M., \& Agustang, A. (2014). The Pattern of Cooperation and Poorness: A Seaweed Farming Community in Indonesia. International Journal of Academic Research, 6(5), 239-242.

Sumai ${ }^{1}$, S., Agustang, A., Adam, A., \& Obie, M. Resilience in Children of Drug Abuse Families: A Case in Pattingalloang, Makassar City, Indonesia.

Sutrisno, S., \& Agustang, A. (2018). PERANAN PENGAWAS SEKOLAH TERHADAP $\begin{array}{llllll}\text { PELAKSANAAN KURIKULUM } 2013 & \text { DI } & \text { SMA } & \text { NEGERI } & 17\end{array}$ MAKASSAR. JURNAL SOSIALISASI, 100-105.

Syukurman, S. (2020). Peluang dan Tantangan Lembaga Pendidikan Islam. EDU SOCIATA (JURNAL PENDIDIKAN SOSIOLOGI), 3(2), 71-87. 
Tumba'Arrang, G., \& Agustang, A. (2020). Pergeseran Pemaknaan Rumah Ada Tongkonan Dan Alang Pada Masyarakat Toraja. Phinisi Integration Review, 3(2), 150-164.

Tinri, M. D. N., Akib, H. H., Agustang, A., \& Jasruddin, H. Hotels and Restaurant Tax Revenues Management.

Urbach, N., \& Agustang, A. (2019). PREFERENSI ORANG TUA DALAM MENYEKOLAHKAN ANAKNYA DI DESA AMOLA KECAMATAN BINUANG KABUPATEN POLEWALI. JURNAL SOSIALISASI, 89-94.

Usmana, A., \& Agustangb, A. The Implementation of “Arif” Social Behaviour within Perssin Supporters in Sinjai District.

Upe, A., Salman, D., \& Agustang, A. (2019). The effects of the exploitation of natural resources towards risk society construction in Southeast Sulawesi Province, Indonesia. Journal of Degraded and Mining Lands Management, 6(2), 1587.

Wahab, A., \& Agustang, A. (2014). INEQUALITY LIFE OF URBAN FISHERMEN. International Journal of Academic Research, 6(4).

Wihdania, W., \& Agustang, A. (2020). Pernikahan Tolotang Di Kelurahan Amparita Kecamatan Tellu Limpoe Kabupaten Sidenreng Rappang. Phinisi Integration Review, 3(2), 165-172.

Yakobus, I. K., Kasnawi, T., Agustang, A., \& Gani, H. A. Hybridization of the Poso Conflict Resolution Discourse.

Yunus, M., Edward, M. T. K. A. A., \& Poelimbongang, L. (2013). Social Changes in Coastal Community Affected by the Conversion of Environmental Resources. Research on Humanities and Social Sciences, 3(18), 57-62 